\title{
GENDER PORTRAYALS BY INDIAN BRANDS
}

\author{
Ray, K \\ Dum Dum Motijheel College, Kolkata, India
}

\begin{abstract}
Gender representation on the smallest scale has always been important for one to understand what it means to be male or female. So to look at it in terms of advertising (possibly considered the most powerful and influential medium in this ever-increasing commercial society) is to look at it with a more serious eye. From the images inflicted upon us in the patriarchal mass media that surrounds us, it is assumed that we have been encouraged to mould ourselves into a set ideal. For a woman, it means having beauty, elegance, passivity and good domestic ability and for a man that means being tough, 'rough n ready', competitive and business minded. Sitting in the $21^{\text {st }}$ century however, it would seem too many that these ideals are no longer essential in gaining acceptance into society although they may still be prevalent. Today, women are frequently self-reliant and career focused whereas many men 'feel they have the right to self-expression and self-indulgence, to love and be loved'. This paper tries to examine the actual portrayal of women by few established brands in India
\end{abstract}

Keywords: gender, female, portrayal, brands, images.

\section{INTRODUCTION}

Gender representation on the smallest scale has always been important for one to understand what it means to be male or female. So to look at it in terms of advertising (possibly considered the most powerful and influential medium in this ever-increasing commercial society) is to look at it with a more serious eye. From the images inflicted upon us in the patriarchal mass media that surrounds us, it is assumed that we have been encouraged to mould ourselves into a set ideal. For a woman, it means having beauty, elegance, passivity and good domestic ability and for a man that means being tough, 'rough $\mathrm{n}$ ready', competitive and business minded. Sitting in the $21^{\text {st }}$ century however, it would seem too many that these ideals are no longer essential in gaining acceptance into society although they may still be prevalent. Today, women are frequently self-reliant and career focused whereas many men 'feel they have the right to self-expression and self-indulgence, to love and be loved' (Barthel 1992:148). ${ }^{1}$ The new man and new woman might be present in today's society but to what extent are television advertisements an accurate account of this new lifestyle? The main focus will centre on few main groups of television advertisements: The household product advertisements and the beauty advertisements.

\section{The Household Product}

Over the past decade, more and more women have either been ignoring the housework altogether, or combining it with a career. Today $54 \%$ of woman with pre-school children, are (largely accepted as being due to the feminist movement) either in full or part-time employment (Social Trends 2000²). And to compliment this, an increasing amount of househusbands are emerging. Given these facts then, why is it that women still stand as the predominant feature in household product commercials? According to Dow (1995:200, cited in Holtzman $2000: 80^{3}$ ), 'one of the reasons why television is resistant to the messages of feminism... is that they (sponsors) view those messages as conflicting with woman's desire to consume.' Advertisers do not want to present a liberated woman because this new woman does not want and thus will not buy their products. For this reason the advertisers' homely woman image lives on.

Another reason for this could be the fact that men dominate the workplace. $3 \%$ of directors in general are women. (Paten, 12 $2^{\text {th }}$ March 2002) . The $^{4}$ The advertising industry itself has particularly high men to female ratio. Based on statistics produced in Campaign November $11^{\text {th }} 1983$ (TCU report $1984: 23^{5}$ ), it was revealed that only 17 out of 244 
advertising directors were women and in an industry so greatly dominated by men is it not likely that consciously or subconsciously the adverts produced will be biased? Even with the bigger freedom of choice given to women nowadays we are still to a certain extent living in a patriarchal society which looks through the male gaze. Women are still being portrayed as being dependent on men. In the most recent Toilet Duck advertisement for example, the housewife's attempt at cleaning the toilet proves unsuccessful. The voice-over (female) tells us of Toilet Duck who provides active tablets to wash away the grime. It is not explicitly stated but by his top hat and tails we are encouraged to believe him to be male, indicating that the woman needs a man to invent products in order for her to do the work well. The man is the adviser and the woman shows her gratitude by blowing him a kiss. She could not do it without him, resulting in the traditional message that women need men. Voice-overs represent authority and it has been reported that over $94 \%$ of voice-overs are male. (Chandler, 1998) ${ }^{6}$. The use of a female voice indicates that voices of women are coming to represent knowledge and intelligence. Yet, female voices are really only used for advertising household products, 'women's products', advertisements which encourage 'flattery to hail women as experts well versed in the finer points of household management (Macdonald 1995:78) ${ }^{7}$.

\section{The Beauty Advertisement}

Women have always been very beauty conscious and insecure about their appearances and advertisers have exploited this by bombarding them with ways in which to 'improve themselves'. In recent times however, the introduction of western terminology such as 'independence' and 'intelligence' in association with women has helped their liberation. Threatened by these terms, the Japanese have overcome them by 'interpreting them against the background of traditional values,'(Tanaka 1994:131) ${ }^{8}$ using these terms to encourage the female to gain independence but only through buying products. A phrase which they used in an advertisement was: 'Chiteki-de joohinna shiruku burausu', meaning 'An intelligent and noble silk blouse.' How is an intelligent blouse possible? They have stretched the meaning of intelligence to encompass impressions of elegance and splendor. They have done this so that women will be conned into believing that intelligence comes through clothes rather than mental study. (Tanaka 1994:110) This thereby seems to conclude that to find any sort of financial success is to start by being beautiful, 'Japanese group ideology and male chauvinism have been rescued' (Tanaka 1994:131).

Pressure on women to look good however is not new but it is only really in the last decade that men too have started to feel pressurized into enhancing their natural looks. Advertising has encouraged a feminization of culture, as it puts all potential consumers in the classic role of the female: manipulable, submissive, seeing themselves as objects. If women's advertisements cry "Buy this product and he will notice you" men's advertisements similarly promise that female attention will follow immediately upon purchase'(Barthel 1992:148).

A current example of this is the Gillette advertisement Mach 3. (A razor.) A handsome, topless, muscular man shaves with a Mach 3 , cuts to demonstration of the blade shaving smoothly to the skin, cuts to a beautiful woman feeling his smooth face. A female voice-over tells the male audience of the razor's attributes: a close shave but (possibly more important for a man) the appeal this look will have for a woman: 'You'll love the difference and so will we.' In this instance a female voice-over is used for a product outside the household, but it does not stand to represent the intellectuality of women, it is only used to play on men's emotions, to try and encourage them to buy the product because this supposedly will get the girl.

To a fair extent, advertisers have been changing their campaigns to correspond with changing lifestyles, demonstrated in the respect that on television advertisements we see men as well as women doing the housework and wanting to look beautiful. Despite this however, according to the study, 4/6 people believe that television advertising's portrayal of men and women is not an accurate portrayal of society whereas $2 / 6$ people are unsure. This suggests that the advertising industry has a long way to go if it is to paint us a picture of the sexes that we are going to recognize in our everyday lives. At the same time however, it should be considered that the advertising industry (in general) is not there to meet our social needs but is there to make sales and deal with big 
money ${ }^{10}$. Their power comes from our pockets, and as long as we keep buying, they are not going to change a thing.

\section{Examples of Television advertisements with unnecessary women portrayal in India:-}

Seven advertisements that had women representation in them were identified for the survey. The advrtisements identified were:-

- Amul Macho,

- The Axe Effect,

- Amul Manthan Story,

- Virgin Mobile,

- J.K. Super Cement,

- Slice

- Parle Hide n Seek.

The survey was broken into two parts, Part A consisted of 8 close ended questions and part B had a rating system of popular TVCs in order of relevance, likeness, requirement of use of women and storyline on a scale of 1 to 10 wherein 1 was considered least likable and 10, most likable.

\section{Survey Analysis Part A}

1. 1. Do you find the presence of skimpily clad women in commercials for products, like-invertors/cement etc relevant? $21 \%$ said yes, $79 \%$ said no.

2. 2. Have you ever bought a beauty product after watching its commercial? $60 \%$ said yes, $25 \%$ said No, $15 \%$ said maybe.

3. 3. Have you ever felt insecure about your body while watching a commercial on TV? $45 \%$ said yes, $55 \%$ said no.

4. 4. Do you think there is an influx of commercials containing sexual content in the last 5 years?

$80 \%$ said yes, $12 \%$ said No, $8 \%$ said maybe.

5. 5. Have you ever felt a major impact on yourself by an advertisement? $30 \%$ said yes, $55 \%$ said No, $15 \%$ said maybe.
6. 6. Do you think that indecent representation of women in Indian advertisements may have led to increase in crime against women? $28 \%$ said yes, $40 \%$ said No, $32 \%$ said maybe.

7. 7. Do you feel uncomfortable with modern protection/anti-pregnancy pills and sanitary products advertisements? $28 \%$ said yes, $62 \%$ said No, $10 \%$ said maybe.

8. 8. TVCs for modern protection and sanitary products etc. raised sexual awareness or vulgarity. 50\% said Sexual Awareness, 35\% said Vulgarity, and $15 \%$ said neither.

\section{Survey Analysis Part B}

Part B of the questionnaire was calculated by finding Arithmetic Mean more commonly called average. The overall ratings given to each of the 7 advertisements are:-

Name Ratings

Amul Macho

The Axe Effect-

Amul Manthan Story-

Virgin Mobile-

J.K.Super Cement-

Slice-

Parle Hide $n$ Seek-

It can be seen from the average ratings that television viewers look for content in television commercials, not blind use of women just to add oomph or glamour factor.

Students and young professionals are more articulate about indecent exposure of women in TVCs. On the other hand, housewives and middle-aged respondents are more tolerant towards any such TVCs. More than 50 percent of professional in metros believe that advertisements have not been able to portray the actual status of women in India, there is a strong sentiment that education, financial independence and decision making power have helped to bring about a change in portrayal of women. But on the flipside some of them (20\%) also consider independent women to be too modern 
In general, respondents in the age group of $15-25$ years of age are more critical about TVCs than those in the age group of 26-40 years of age.

It can be seen from the survey conducted that younger generation of today that is more professionally and politically active and aware have strong views and decision making abilities. They are intolerant towards superficiality of any kind, including that of television and commercials as a whole and are critical about issues such as brand value; consumerism and propagandist nature of advertisements. The survey was conducted with a random sample size of 40 people in the age group of 15-65 years from across the country.

The bottom line is that a woman in Indian society commends respect and admiration. She is being adored and respected from time immoral. But the small screen for sake of entrainment is responsible for women's image for being tarnished for the benefit of few. Television is being view widely from villages to major cities and also viewed by all. When women are being portrayed in this way it is giving negative impact on young minds, which is damaging our society. For decades women have been portrayed as housewives, dependent on men \& sex objects in advertisements. Silverstein and Silverstein in their study on television commercials marked that:-

1. Men are usually announcers, due to the attributed "voice of authority and trust."

2. Women were shown in the home with greater frequency than men.

3. Men were more likely to give advice to women

\section{A woman's occupation was rarely evident.}

5. Women were eight times more likely to be as portray subservient roles in their interactions with men.

However from past one decade, representation of women in advertisements has been experiencing a shift from the house wife centric advertisements to the career women advertisements. Research shows a consistent picture of gender stereotyping as portrayal of adult women have stressed on passivity, deference, lack of intelligence and credibility, and punishment for exerting significant effort. On the other hand, men have been shown as constructive, powerful, autonomous and achievement oriented ${ }^{11}$ Also, it looks into how in spite of this slight shift, women still are dominantly restricted to the age old gender constructions and traditional roles.

The advertisement for a certain shampoo on the Television portraying two of the most sensuous and physically attractive star models, (who were once an off-screen pair in real life) is an indicator of how sex roles have changed in Indian advertising. Cinematographed in monochrome with the right shades of darkness and mood lighting, the word 'hot' recurs like a double-edged metaphor in the advertisement, an adjective that has no direct relationship with the product being advertised.

This and other contemporary advertisements raise pertinent questions about perspectives on gender in media representations of men and women. The Bipasha Basu-John Abraham advertisement mentioned above for instance, underscores how men in Indian advertisements are being presented in a much more macho-dominant manner than they were before. Another advertisement for male underwear shows a number of females with pseudo-coy expressions on their faces coming out of a toilet. The camera cuts to a shot inside the toilet where a handsome male model lies prostrate with telltale lipstick marks across his body. Again, the product advertised does not really bear a direct relationship with the message or the script since few Indian males would be caught dead before females catch them in their underwear inside what appears to be a public toilet! These are Western concepts imposed on Indian advertisement scripts and prove that visuals need not necessarily represent the social norms of a society.

On the other hand, while sports and athletics sported more men than women in the past in India and in the West, today however, real achievers like Sania Mirza have changed all that. Also, you may see a cricketer like Mahendra Singh Dhoni as often as you see Mirza, never mind the product they are posing for. Women in Indian advertisements are being presented in less dependent roles than they were before. An advertisement for a leading women's fortnightly recently carried a delightful image of an ageing 
woman in bridal attire. It later transpires that her daughter is getting her married again! This is an example of positive advertising that subtly carries a social message. Many mother-daughter advertisements in recent times bear out female bonding, in effect, subtly marginalizing the role of men by cutting them out completely from such advertisements. Yet, women do not appear in advertisements for 'solid' products such as steel and cement and even if they do, they are sidetracked within the script.

This area is marked by a paucity of research, but a study authored by Mallika Das ${ }^{12}$ revealed interesting findings.

The Sex Roles study drew similarities and differences in the way women and men are portrayed in Indian magazine advertisements and the way they are portrayed in other countries. The similarities, according to the study, largely borne out by fact seem to be that (1) overall, men and women in Indian advertisements are also portrayed in stereotypical ways; (2) the stereotypes in India also seem to be changing and softening, albeit slowly; (3) as in the case of western advertisements, women and men appear for different types of products in Indian advertisements; and (4) role portrayals seem to be affected by the nature of the product in the case of women, as in other nations.

In the case of male role portrayals, the following major differences were found:

1. The study quoted an earlier 1997 US study (Kolbe and Albanese) which found that men were often portrayed in athletic roles. By comparison, the study recorded that only 11.4 per cent of Indian advertisements showed men in such roles. This percentage was less than 9.5 per cent in previous years.

2. Although men in Indian advertisements appeared more often in traditional ways, the study also recorded that men were not portrayed in very negative ways. This seems contradictory to findings from other nations, where male portrayals have changed to a lesser extent than female role portrayals over the past few decades.
In addition, there is an increased appearance of men in Indian advertisements. This may be attributable to a number of factors. First, India is one of the fastest growing markets for consumer durables and several "male-oriented" products such as insurance, medical, industrial, and technology-related products. Because men are more often considered to be the primary decision makers for such products, the increase is understandable. Second, the number of advertisements in business and general interest magazines in India has increased tremendously while the number in women's magazines has not. Both of these factors could have led to an increase in the number of men appearing in Indian advertisements.

Three, the increased visibility may also be attributed to stars, sportsmen and celebrities from different fields stepping into the modeling world. No one would have dreamt of Amitabh Bachchan modeling for any product when he was at the peak of his career as hero. Today, he is modeling for nearly 70 products across the board. Female stars were popular as models earlier, and this has changed. Today, male stars from Shahrukh Khan to Amir Khan to Akshay and Aftab, and even smaller names like Irfan Khan, Zayed Khan and Emraan Hashmi are into modeling. Those who were already models but are now celebrated stars such as John Abraham are chased by agencies to function as brand ambassadors.

Two major differences in female role portrayals are common;-:

1. Some of the common stereotypical portrayals seem less prevalent in Indian advertisements. For example, unlike in British magazine advertisements, women in Indian magazine advertisements were more likely to be portrayed in "neutral/other" ways and less likely to be portrayed as sex objects. Women modeling for mobile phones, cars and two-wheelers, painkillers, and as protagonists carry neutral portrayals. Women were also less likely to be portrayed in "dependency" roles in Indian advertisements than in British advertisements. It is noteworthy that these results are similar to those found in two other Asian countries-Korea and Japan--where, again, females were less likely to be portrayed in very negative stereotypical ways than in western nations. As mentioned earlier, the religious and cultural differences between India and western nations may account for this finding. 
2. The polarizing trend found in the West, i.e., a tendency to portray women in dependency and housewife roles and in nontraditional activities, career-oriented, and authority figure roles (in British magazine advertisements), was not found for India by a' study. 'Polarizing' means strong opposites where one woman is shown driving all alone in a car with an expression of confidence on her face juxtaposed against the image of a woman sensually posing for a cosmetic product or spouting forth the advantages of a health drink for children. In India, the trend seems to be to portray women less often as housewives or concerned with looks, but not more often in nontraditional, career-oriented, or authority figure roles. Instead, there seems to be an increase in neutral portrayals of women, due, in part, to the dramatic increase in the number of advertisements for such products. $^{13}$

This might be attributable to the fact that although Indian society is changing, it is still a patriarchal society and dramatic changes (such as portraying women in non-traditional ways) may not be accepted as easily in Indian society as in western ones. One classic case is that of Unilever where for a product (AXE) there is a 'Hot Girl' ideal and for another (DOVE) it spoofs the same principle. Any change in role portrayals of women have to be done while being posited clearly within dominant ideology, not from without. Furthermore, as studies by G Ramu (1988) ${ }^{14}$ and S Bharat (1995) ${ }^{15}$ had found, Indian men and women, regardless of their educational level or career status, hold conservative perceptions of women's roles within the family.

Thus, although portraying women in neutral ways may be acceptable to Indians, portraying them in nontraditional ways may not be. Besides, there is an increasing trend in 'family' and 'couple' representations in advertisements for consumer durables like washing machines, refrigerators and micro-wave ovens, products earlier dominated by women alone.

Still, with the increasing number of female models shown in advertising today, the media seem to give more equality to female images, but the underlying messages still emphasis sexuality, often presenting women as sex objects. Also, the number of women in "decorative roles" had actually increased over time, according to a 1993 US study by L J Busy and G Leichty. ${ }^{16}$

The challenge faced by advertisers presently is to portray women realistically in diverse roles, without alienating any segment of women. Experts agree that today's women wants to see women portrayed with a new freedom, but also as a mature, intelligent person with varied interests and abilities. ${ }^{17}$ But the advertisers to make a product attractive, associate their product with an 'attractive' image. This is always a woman, who provides the "desirable" image for the ad, irrespective of her relevance to the advertisement. In the advertisements for "Blenders Choice" 18 liquor \& "Hindware Sanitary ware"19, the women are just means to attract attention. .The Blenders choice advertisement portrays the woman as a thing to be tasted and the Hindware advertisement strategically places the product on the women's breast. Both advertisements merely objectify women.The women have no relevance whatsoever to the product that iis being promoted. Women are also portrayed in advertisements as unthinking beings preoccupied with trivial matters. The advertisements for "Ansal Plaza"20 \& "Grooms In"21, portray them as shallow, and have mundane thoughts such as shopping and good clothes. The tag line in an advertisement illustrates "Her husband has an extramarital affair and she knows it", so as to say that she is not worried or bothered about her marriage as much as she is about her shopping in the mall. In another advertisement, two brides are 'willing' to marry the groom, for he is wearing the salwar suits manufactured by their brand.

The women in most advertisements for women's attires are highly sexualized especially so in advertisements for jeans. The advertisements for "Levis red loop"22 which one can see on many billboards of Bangalore, show the model wearing "just" the jeans and covering her torso with her hands. The "Lee cooper "advertisement ${ }^{23}$ shows the female model again "covering" her upper part of her body with a bead necklace. Why must be a woman's torso be exposed for advertising a pair of jeans? The bodies of women have been reduced to an object of exploitation for the male sexual urge in such advertisements.

Some of the misconceptions that are read, by the target audiences as pre-requisites for women to be 
considered beautiful are to be thin and perfectly toned with flawless skin as illustrated in advertisements for Skin care, Health \& Beauty clinic ${ }^{24}$. One of the popular readings is that, women need to be 'embarrassed' if they are not thin. These advertisements make women feel insecure about them. The women in these advertisements, who are 'doctored' to appear perfect, are taken up as role models .These advertisements vicariously influence societal notions about beauty which in turn pressurize women to resort to the stereotypical mould.

The typical portrayal of the housewife, as dependent on her husband is still prevalent in advertisements. The "ICICI" Insurance advertisement ${ }^{25}$ urges a man "to give his shoulders the satisfaction of protecting" his wife. The wife in the advertisement is shown resting her head on her husband's shoulder so as to represent her dependence on him. The woman is shown as someone rather "incapable of looking after herself and requires a husband to do so" 26

Another advertisement 27 welcomes "Home Ministers" to their furniture showroom "Nu Looks" to check out the new "modular kitchens". Although women are beginning to be economically independent, the advertisements continue to delineate domestic arena as the rightful place for a woman. Women celebrities are used as brand ambassadors for endorsing products. Even here, their sensuality is emphasized upon rather than their talent as a celebrity. Their achievements are not focused on enough. For example, a few of "Malaika AroraKhan's" advertisements talk about her curvaceous body rather than her success as a video jockey, or an actor. Such advertisements promote the notion that, in order to be successful one should have 'beautiful' bodies. However there are a few exceptions. The "Movado" advertisement ${ }^{28}$ features "Twinkle Khanna" as a successful award-winning actor. The text in the advertisement associates the actor's artistic talents with the products quality. Her brand image as being the talented successful actor is stressed on to promote the product. We also have The Allen Solly advertisement $^{29}$ portraying women as independent, educated \& successful but such positive portrayal of woman is very limited.

The portrayal of woman has not changed much over the years. Women in advertisements represent what the society holds as an ideal image of her. Women are continued to be predominantly portrayed as sexual beings, unthinking, dependent, caretakers, preoccupied with beauty. . Advertisements perpetuate the notions of femininity \& reinforce them every time these advertisements are read or watched by the audience.

Since the last few decades have seen tremendous changes in the lifestyles of men and women across all over the globe and particularly so in our own country. Globalization, market economics and above all, fast strides in technology have affected virtually all facets of life be it religion or education, politics or employment, fashion or health care. With the advent of computers and telecommunications, media has also undergone a sea of change. Media in India, which until a few years back used to comprise of the morning newspaper, the radio broadcasts and the sole Television network screen images of "Doordarshan", comprises today of a dazzling and at times mind boggling array of communication devices. The media, which was earlier merely a reporting device, is today a vibrant means of shaping, molding and influencing public opinion.

However, in spite of all these changes, the media has not managed to overcome the typical stereotypes that are associated with women in India. While there are certain departures from this, the fact remains that by and large, there is a huge potential for better and a more realistic projection of women. It does not require any detailed analysis to conclude that the media is in a state of confusion and are perhaps unsure of the way they want to see women. On the one hand they still have this eternal image of a woman who is confined to the boundaries, duties and responsibilities of her home and her family. Even a contemporary television advertisement, like that of "MOOV" is based on the same philosophy. The lady in this advertisement is shown as the single person doing all the housework, and attending to the whims and fancies of all her family members, from her husband to kids, to mother and father-in-law, and simply everybody. She is allowed a break from her work only when she cries out in pain from a backache. And then the family decides to recognize her presence by passing a tube on ointment around, and the husband offering to apply the ointment for 
her. But those moments of respite are few, as she is back on her feet the moment the pain recedes, and the bombardment of orders and requests begin again. The docile, subservient nature of the woman is apparent, although not meant to be so perhaps.

Another image of women in India that has grown in the recent years is the one that we have aped from the west and which gradually is gaining momentum. This is the portrayal of the woman as a showpiece or an icon of glamour. We hardly come across an advertisement these days where we don't see a pretty model beaming at us, be it the advertisement of a new model car or that of a cold drink. We see the advertisement of the new "Maruti Zen" where the tiger stalks a young woman in a dark alley. The advertisement had to be withdrawn due to public pressure. In other words, the portrayal of women in the Indian media oscillates between these two extremes: the "mother India" and the "glamour girl" image.

What the media does not see and project is the image of a woman as a serious partner in decision-making, a serious contender as a professional: doctor, engineer, teacher or a computer specialist, a serious politician or leader. This is so in spite of the fact that we have today a large number of working women, and there is hardly any field that does not have women representatives. We have women administrators, entrepreneurs, doctors, police women, computer specialists, politicians and most surprising the entire media business is full of women practically performing all types of activities.

It is indeed a very sad phenomenon. For example, companies like Wipro, Infosys, IBM, Microsoft etc employ almost equal number of men and women. But when it comes to a television advertisement regarding computers, we always find that it is the projection of a man behind the monitor!! The woman has to use 'fair \& lovely' and wear a pink dress to become a cricket commentator.

There is no end to such examples and though as a nation and we have progressed by leaps and bounds, the fact remains that the usage of women as perceived in our country oscillates between these two extreme stereo types.

\section{Challenging Stereotypes}

Recent positive signs from advertisements suggest that they are doing what cinema could not do as they continue to portray stereotyped images in the movies:-

- The Kohima Ad (KBC promo):- Here a girl from North-East skeptically asks the host-How many people actually consider North-East to be a part of India? She actually makes a statement about the negligence of the Indians about the NorthEastern states.

- The Live-In Ad: - Here the advertisement depicts a couple living-in. The screen also flashes the word "Move on."

- The Second Marriage Ad (Jewellery Brand):- The advertisement shows a mother and daughter getting ready for mother's second marriage. During the ritual the groom lifts the daughter and the three complete the 'pheras'.

- The Wife is Boss Ad (A mobile service provider):-In this commercial, the lady boss wants a certain assignment to be completed and is firm about that when the man requests her if he can finish the project later. At home she calls up her husband who is the same man and here she is a loving wife asking her husband to come home before dinner gets cold.

- The-Come-Out-of-The-Closet Ad (A clothing Brand):-This is the first lesbian advertisement in India. Here two girls come out of a closet both in the process tugging on their clothes. Tagline reads"Come out of the closet. Move on."

- Marriage Pressure (A Watch Brand):- This advertisement tells women not to get pressured into marriage.

- Appreciation to mothers (A Health Drink):-Applauds mothers for raising active and capable daughters.

- Women Empowerment (Insurance):-A young daughter writes a cheque for her dad's new car with her own savings and 
her dad accepts after an initial hesitation with a look of pride on

\section{The Importance Of Media Literacy}

The danger in all this is that the age of Information and entertainment is still relatively new, and how our constant and growing use of media is affecting us in ways big and small may be easily overlooked. We get used to things very easily, and often the many media images and messages we see and hear enter our brains very quickly, and on a subconscious instead of conscious level. Experts call it passive vs. active processing of information.

This is precisely why it is important to stand back and notice what is going in to our eyes and ears and our brains, how much and how often, how it might affect what we think about, how we think about it, and what we do. This is called Media Literacy or Media Education or Media Awareness. Media Literacy teaches people to analyze messages conveyed by the media, consider the commercial or political purpose of the image or message and who is responsible for it, and other ideas that it implies. It increases our ability to react to and appreciate (or not) media images and messages in a genuine and conscious way. It provides information and statistics on media and culture, and provides a set of tools for critical thinking that can be applied to any media "product" or setting. It is a movement in education and culture that is growing alongside the growth and expansion of the media, each day throughout the country and the world.

It is true that things have changed in a big way for women in the last thirty years due to lots of women (and some cool men) speaking out and acting for progress and equality for women and girls, there's more that needs to be done. We've got all sorts of new, 21st century kinds of challenges---and old problems that still need lots of our attention and energy. These include: good health; genuine selfesteem; understanding of and comfort with sexuality; relationships based on mutual respect and equality; safety from domestic and sexual violence; goalsetting and career success; sound financial judgment; educated participation in government and democracy; and overall power-sharing in society for women and girls.
Lessons in media literacy, articulated clearly or indirectly through public service advertising, posters and so on, can empower women and girls to handle problems that result from a fixation on physical attractiveness rather than on intellectual growth, on wholesome good health rather than on stringent dieting that could lead to chronic psychological trauma like anorexia nervosa and so on.

In the meantime, gender roles in Indian advertising continue to change. Taking celebrities as an example, Amitabh Bachchan is advertising for a brand of diamonds that across the world till this day is known as a woman's best friend. Bachan's role is a kind of revolution, since even today, every other diamond advertisement on the small screen and the print media exclusively uses women as main models.

The primary focus in images of Indian women changed from portrayals of women as domestic housewives and mothers, to women as sexual beings who often work outside the home and who have become westernized. Drawing on the concept of cultural hegemony, a content analysis is carried out of the top 10 rated programs being broadcast on private Television networks in India in July 2007. It is found that women are gaining greater visibility in Television programming. However, the characters are constructed primarily through patriarchal and nationalist interests, often reverting any progress made in gender-role portrayals to a more traditional status quo ${ }^{30}$. There is also evidence of the process of cultural hegemony being manifested through mass media channels.

\section{REFERENCES}

Barthel,Diane, 1992, 'Men, media and the gender order when men put on appearances. Advertising and the social construction of masculinity'. In Craig,Steve, Men, Masculinity, and the Media. Research on men and masculinities, Sage

SocialTrends2000, LabourMarketTrends, March 2002: 'Women in the labour market', www//statistics.gov.uk

Holtzman, Linda, 2000, Media Messages, What film, television, and popular music teach us about race, class, gender and sexual orientation. New York: M.E.Sharpe

Paten, Heather, Tue 12th March 2002, Shopland, Radio 4

TCU report, 1984, Images of Inequality. The portrayal of women in the media and advertising.

Chandler, Daniel, 1998, notes on television and gender roles, [www document] URL 
http://www.aber.ac.uk/media/Modules/TF33120/gendertv.h tml

Macdonald, Myra, 1995, Representing Women, Myths of Femininity in the Popular Media, London: Edward Arnold

Tanaka, Keiko, 1999: Advertising Language: a pragmatic approach to advertisements in Britain and Japan, London: Routledge

Strate, Lance, 1992, 'Beer commercials, A Manual on Masculinity'. In Craig, Steve, Men, Masculinity, and the Media. Research on men and masculinities, Sage

Jhally, Sut, 1990, "The Codes of Advertising, fetishism and the political economy of meaning in consumer society". New York: Routledge

Daniel.J.Brett and Joanne Cantor "The Portrayal of Men and Women in US television Commercials" pp595-608

Das Mallika "Study in Sex Roles: A Journal of Research "under the auspices of Mount Saint Vincent University, Halifax, Nova Scotia, Canada, at the Department of Business Management, Tourism and Hospitality Management.

Munshi.S, "Wife/mother/daughter-in/law: Multiple avatars of homemaker in 1990s Indian advertising." Media, Culture and Society, 2000.

Ramu.G, "Marital roles and power: Perceptions and reality in an urban setting". Journal of Comparative Family Studies, 1988.
Bharat.S, "Attitudes and sex-role perceptions among working couples in India." Journal of Comparative Family Studies, XXVI (3), 1995.

Busy L J and G Leichty G, "Feminism and advertising in traditional and non-traditional women's magazines 1950s1980s," Journalism Quarterly, 70(2), 1993

Lyne Folse,- "Workers Labor to raise Women's Status". Advertising Age (September 12, 1985) pp 36-38

Blenders Choice Liquor advertisement.

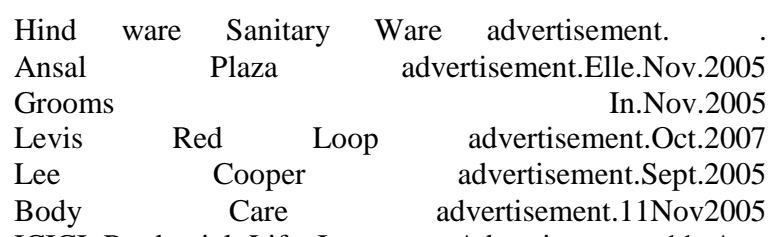

ICICI Prudential Life Insurance Advertisement. 11 Aug 2008.

Special correspondent: "Advertisements' demeaning women' draw AIDWA's ire."The Hindu, 19 th Sept.20 02, New Delhi, edition Nu Looks.Advertisement.11Nov2005

Movado Advertisement, Allen Solly Advertisement, Dec. 2005

Sheena Malhotra and Everette.M.Rogers article Satellite Television and the New Indian Woman. International Communication Gazette, Vol. 62, No. 5, 407-409 (2000) 